\title{
Hybrid Particle Swarm Optimization and Gravitational Search Algorithm for Economic Dispatch in Power System
}

\author{
Amal Abdulrahman Juma Al Raisi \\ Department of Process Engineering, International Maritime College \\ Suhar OM, Oman \\ amalabdulrahmanj@gmail.com
}

\begin{abstract}
This paper has developed a novel Hybrid Intelligent approach based on the Particle Swarm Optimization and Gravitational Search Algorithm named HPSO-GSA to optimize economic dispatching of the electric power system. Based on the widespread dispatching optimization technique, the objective of reducing pollution, emission coal utilization, and purchasing cost is calculated. To resolve the combined weighted dispatching optimization technique is used these Hybrid Algorithms for five units and 10 units correspondingly.Taking into consideration of system's active power balance, unit minimum runtime, node flow balance of power system, and downtime constraints, and transmission capacity constraints, negative and positive reserve constraints, unit output constraints, node voltage constraints, unit output power rise rate constraints, etc.
\end{abstract}

Keywords: Economic Dispatch; Optimization Technique; Power Balance; Constraints; Case Study

\begin{tabular}{ll} 
Nomenclature & \\
\hline Abbreviations & Descriptions \\
\hline ELD & Economic Load Dispatch \\
PSO & Particle Swarm Optimization \\
ED & Economic dispatch \\
ACO & Ant Colony Optimization \\
WG & Wind Generation \\
LMBPA & Levenberg-Marquardt back-propagation algorithm \\
BESS & Battery Energy Storage System \\
BSO & Bee Swarm Optimization \\
AIS & Artificial Immune System algorithm, \\
LCED & Linearly-Constrained Economic Dispatch \\
HS & Harmony Search \\
OPF & Optimal Power Flow \\
DE & Differential Evolution \\
\hline
\end{tabular}

\section{Introduction}

The main global problem in electric power with the large interconnection of networks is considered. The important concern over the circumstance is because of its continual rise in cost. Hence, it is a large crucial to minimizes the prices of electric power. This is highly based upon the important minimization in the number of fuel utilization and the functioning charge of the electric power plant. Hence, the main objective of an electric power plant is to present maximum quality electric energy with the minimum probable cost when fulfilling diverse constraints and limits. In the power plant, these constraints and limits are devised as the ELD problem [1]

In power system planning and operation, ED plays a significant role, has accepted important concentration in contemporary years [2]. The main reason for ED is to plan pledged generating unit outputs to concurrently reduce operating cost and convene the power system load demand when fulfilling all inequality and equality constraints. Conventionally, an estimated quadratic function is used to produce the mathematical formula of ED problem convex to minimize the computational crisis. 
Nevertheless, in reality, on the other hand, multi-valve steam turbines create input-output curves of generators essential available mainly nonlinear typical [9]. Conversely, machines fault themselves or related auxiliaries forbid generators from operating in few zones. Hence, ED solution space issue by means of the existence of valve-point effects and banned operating zones is mainly discontinuous and nonlinear, creating the optimization stiff to be manageable. In existing solution algorithms such as linear programming, dynamic programming, Lagrange relaxation, quadratic programming, nonlinear programming, and interior point approach are same as to experience dire crises and challenges mostly because of their heavy imposition of several limitations like convexity, continuity, and differentiability on the objective models, and maximum sensitivity to the start values of complicated optimized variables [8].

Emissions from the fossil fuels utilized by power plants lead to maximized operational costs, and needing huge concentration to least the pollution. Since 1990, the ED problem is represented, while ED was approved by the Clean Air Organization to mage the environmental pollution, such as NOx, SO2, and $\mathrm{CO} 2$. Several techniques were used to minimize the emissions and the diverse schemes used to minimize the emissions [10].

In the 1980s, the ED problem was developed; various optimization approaches and processes were exploited to solve the ED problem with complex objective models or constraints. There were a number of traditional techniques which was used to resolve this issue like the gradient projection method, lambda iterative method, dynamic programming, Lagrange relaxation, linear programming, and interior-point technique [11]. One of these techniques is not used for non-convex or non-smooth cost functions [12]. To overwhelm this issue, numerous heuristic optimization techniques were utilized to resolve the ED issue; such as PSO, HS, ACO, AIS, LMBPA, technique, DE, and BSO approach between others. Numerous of these approaches were shown their efficiency in resolving ED issues without any or minimum limitations on the shape of cost function curves. These techniques resolve the ED by using the first population of individuals each of that indicates a candidate solution for the issue. Subsequently, they develop the initial population by efficiently using a set of operators on old solutions to convert them into novel solutions.

\section{Literature Review}

In 2017, Lu Bai et al [1], worked on a distributed control approach to resolve the ED issue. The generators work cooperatively to reduce generation costs when balancing demand and supply without a central control unit. Moreover, the developed technique was on the basis of the consensus protocols and the saddle point dynamics.

In 2018, Zhiyuan Tang et al [2], presented a new consensus-based technique to resolve energy management issues for islanded microgrids. Taking into consideration of the incremental cost of every agent as the consensus variable and through restricted communication among neighboring agents, the developed model can rapidly converge to the optimal solutions.

In 2017, Ying Zhang et al [3], developed renewable generation and the demand uncertainty to emphasize the requirement for online approaches. Next, the extensively-proposed peak based pricing model shows that the requirement for novel peak-aware scheme designs. Here, these crucial confront and formulate peak-aware online economic dispatching methods were tackled.

In 2017, Muhammad Khalid [4], worked on the implementation, development, and effect of an inventive real-time forecast method on cost and operational revenues of a WG microgrid about a related BESS. An ED model was devised exploiting a predictive optimization policy named receding horizon control, to sell energy to the electricity grid via an energy market. This power dispatch model was capable to integrate multi-step ahead forecasts of energy price and wind power, required to decide the operational profits and income of the WG microgrid.

In 2019, M. Garcia and R. Baldick [5], studied the presumptions needed to make progress the optimal dispatch of non-convex TCED issues from a solution of the general LCED issue. Then the general LCED issue might be multiple minimizes, in that case, few perturbations of base-case state might outcome in large dispatch approximation error was shown.

In 2017, Gang Chen and Zhongyuan Zhao [6] presented a new consensus-based ED method. The method was completely distributed so that the optimal dispatch of energy resources in microgrid was executed in a distributed way. The control of time delays on distributed ED was severely verified. The utmost permissible delay bounds were resulting by using the Generalized Nyquist principle. 


\section{Network Model and Problem Formulation for Cluster Head Selection in WSN}

\subsection{Objective Function}

\subsubsection{Total Fuel Consumption Function}

$$
\mathrm{f}_{1}(\mathrm{H})=\sum_{\mathrm{t}=1}^{\mathrm{T}} \sum_{\mathrm{t}=1}^{\mathrm{v}}\left[\mathrm{l}_{\mathrm{i}} \mathrm{P}_{\mathrm{Hi}}^{2}(\mathrm{t})+\mathrm{m}_{\mathrm{i}} \mathrm{P}_{\mathrm{Hi}}(\mathrm{t})+\mathrm{n}_{\mathrm{i}}\right]
$$

In eq. (1) $\mathrm{l}_{\mathrm{i}} ; \mathrm{m}_{\mathrm{i}}$ and $\mathrm{n}_{\mathrm{i}}$ indicates the constant coefficients typify the utilization curve; $\mathrm{t}$ indicates the period; $\mathrm{i}$ indicates the unit number; $\mathrm{T}$ indicates the number of periods (24, 48, 96, and so on.); $\mathrm{v}$ indicates the number of generator units in power system; $\mathrm{P}_{\mathrm{Hi}}(\mathrm{t})$ indicates the output of the $\mathrm{i}^{\text {th }}$ unit during $\mathrm{t}$

\subsubsection{Oxynitride Emission Model}

$$
\mathrm{f}_{2}(\mathrm{H})=\sum_{\mathrm{t}=1}^{\mathrm{T}} \sum_{\mathrm{t}=1}^{\mathrm{v}}\left[\mathrm{q}_{\mathrm{i}} \mathrm{P}_{\mathrm{Hi}}^{2}(\mathrm{t})+\mathrm{w}_{\mathrm{i}} \mathrm{P}_{\mathrm{Hi}}(\mathrm{t})+\mathrm{e}_{\mathrm{i}}\right]
$$

In eq. (2), $\mathrm{q}_{\mathrm{i}} ; \mathrm{w}_{\mathrm{i}}$ and $\mathrm{e}_{\mathrm{i}}$ represents constant coefficients typify properties of this quadratic curve.

\subsubsection{Electricity Purchase Cost Function}

$$
\mathrm{f}_{3}(\mathrm{H})=\sum_{\mathrm{t}=1}^{\mathrm{T}} \sum_{\mathrm{t}=1}^{\mathrm{v}}\left[\mathrm{P}_{\mathrm{Hi}}(\mathrm{t}) \rho_{\mathrm{Hi}}(\mathrm{t})\right]
$$

In eq. (3), $\rho_{\mathrm{Hi}}(\mathrm{t})$ indicates the electricity purchase price of every unit throughout the $\mathrm{t}$ period, and $\rho_{\mathrm{Hi}}(\mathrm{t})=\max \left\{\mathrm{f}\left(\mathrm{P}_{\mathrm{Hi}}(\mathrm{t}) \mathrm{S}_{\mathrm{i}, \mathrm{t}}\right)\right\} ; \quad \mathrm{N}_{\mathrm{G}}$ indicates a number of registered units in system; $\mathrm{T}$ indicates the predispatching period; $\mathrm{L}_{\mathrm{i}}$ indicates the load forecast for the time period $\mathrm{t} ; \mathrm{S}_{\mathrm{i}, \mathrm{t}}$ indicates running indicator of $i^{\text {th }}$ unit at $t, P_{i, t}$ indicates unit output; $f\left(\mathrm{P}_{\mathrm{Hi}}(\mathrm{t})\right)$ indicates quotation function for $\mathrm{i}^{\text {th }}$ unit at $\mathrm{t}$. If $\mathrm{i}^{\text {th }}$ unit is running at $\mathrm{t}, \mathrm{S}_{\mathrm{i}, \mathrm{t}}=1$; if the $\mathrm{i}^{\text {th }}$ unit is not running at ${ }^{t}$, subsequently $\mathrm{S}_{\mathrm{i}, \mathrm{t}}=0 . \mathrm{P}_{\mathrm{Hi}}(\mathrm{t})$ indicates electricity utilization of $\mathrm{i}^{\text {th }}$ unit at ${ }^{t}$.

\subsection{Constraint Conditions}

\subsubsection{Node Flow Balance}

$$
\left\{\begin{array}{l}
\mathrm{AP}_{\mathrm{L}, \mathrm{t}}=\mathrm{P}_{\mathrm{K}, \mathrm{t}}-\mathrm{L}_{\mathrm{PK}, \mathrm{t}} \\
\mathrm{AV}_{\mathrm{L}, \mathrm{t}}=\mathrm{V}_{\mathrm{K}, \mathrm{t}}-\mathrm{V}_{\mathrm{QK}, \mathrm{t}}
\end{array}\right.
$$

In eq. (4), $\mathrm{A}$ indicates the related matrix in the network; $\mathrm{P}_{\mathrm{L}, \mathrm{t}}, \mathrm{L}_{\mathrm{PK}, \mathrm{t}}$ and $\mathrm{P}_{\mathrm{K}, \mathrm{t}}$, are correspondingly active power flow vector, node active load vector and node active output vector, $t ; V_{L, t}, V_{K, t}$ and $V_{Q K, t}$ are correspondingly node reactive output vector, reactive power flow vector, and node reactive load vector at $\mathrm{t}$.

\subsubsection{System active power balance}

$$
\sum_{\mathrm{i}=1}^{\mathrm{N}_{\mathrm{G}}} \mathrm{P}_{\mathrm{i}, \mathrm{t}} \mathrm{S}_{\mathrm{i}, \mathrm{t}}=\mathrm{L}_{\mathrm{i}}+\mathrm{P}_{\mathrm{i}, \mathrm{t}}
$$

In eq. (5), $\mathrm{L}_{\mathrm{i}}$ and $\mathrm{P}_{\mathrm{i}, \mathrm{t}}$ indicates the system active loss and system load correspondingly at $\mathrm{t}$.

\subsubsection{System Positive and Negative Reserve Constraints}

$$
\left\{\begin{array}{l}
\sum_{\mathrm{i}=1}^{\mathrm{N}_{\mathrm{G}}}\left(\mathrm{P}_{\mathrm{i}, \max } \mathrm{S}_{\mathrm{i}, \mathrm{t}}\right) \mathrm{T}_{\mathrm{i}, \text { on }} \geq \mathrm{L}_{\mathrm{i}}\left(1+\mathrm{R}_{\mathrm{t}+} \%\right) \\
\sum_{\mathrm{i}=1}^{\mathrm{N}_{\mathrm{G}}}\left(\mathrm{P}_{\mathrm{i}, \min } \mathrm{S}_{\mathrm{i}, \mathrm{t}}\right) \mathrm{T}_{\mathrm{i}, \text { on }} \geq \mathrm{L}_{\mathrm{i}}\left(1-\mathrm{R}_{\mathrm{t}-} \%\right)
\end{array}\right.
$$


In eq. (6), $\mathrm{P}_{\mathrm{i}, \mathrm{min}}$ and $\mathrm{P}_{\mathrm{i}, \max }$ indicates minimum and the maximum output of $\mathrm{i}^{\text {th }}$ unit correspondingly; $\mathrm{R}_{\mathrm{t}-}$ and $\mathrm{R}_{\mathrm{t}+}$ indicates the negative and positive reserve rates of the system respectively.

\subsubsection{Transmission capacity constraint}

$$
\mathrm{S}_{\mathrm{i}, \mathrm{t}} \leq \mathrm{S}_{\mathrm{l,max}}
$$

In eq. (7) $S_{i, t}$ and $S_{1, \text { max }}$ indicates the actual apparent power and maximum apparent power of line 1 at $\mathrm{t}$ respectively.

\subsubsection{Unit output constraint}

$$
\mathrm{P}_{\mathrm{i}, \max } \leq \mathrm{P}_{1, \mathrm{t}} \leq \mathrm{P}_{1, \min }
$$

\subsubsection{Node voltage constraint}

$$
\mathrm{V}_{\mathrm{k} \max } \leq \mathrm{V}_{\mathrm{k}, \mathrm{t}} \leq \mathrm{V}_{\mathrm{k}, \min }
$$

In eq. (9) $\mathrm{V}_{\mathrm{k}, \min } ; \mathrm{V}_{\mathrm{k}, \mathrm{t}} \mathrm{V}_{\mathrm{k} \max }$ indicates the minimal voltage, actual voltage and maximal voltage of node $\mathrm{k}$ at $\mathrm{t}$ respectively.

\subsubsection{Unit output power rise rate constraint}

$$
\mathrm{P}_{\mathrm{i}, \mathrm{t}-1}-\mathrm{D}_{\mathrm{i}-} \leq \mathrm{P}_{\mathrm{i}, \mathrm{t}} \leq \mathrm{P}_{\mathrm{i}, \mathrm{t}-1}-\mathrm{D}_{\mathrm{i}+}
$$

In eq. (10), $\mathrm{D}_{\mathrm{i}+}$ and $\mathrm{D}_{\mathrm{i}-}$ indicates the increase rate and output drop of the $\mathrm{i}^{\text {th }}$ unit in one period respectively.

\subsubsection{Unit minimum runtime and downtime constraints}

$$
\left\{\begin{array}{l}
T_{i, \text { on }} \geq T_{i, \text { on-min }} \\
T_{i, \text { off }} \geq T_{i, \text { off }- \text { min }}
\end{array}\right.
$$

In eq. (11), $\mathrm{T}_{\mathrm{i}, \text { off }}$ and $\mathrm{T}_{\mathrm{i}, \text { on }}$ indicates the downtime and runtime of the $\mathrm{i}^{\text {th }}$ unit respectively; $\mathrm{T}_{\mathrm{i}, \text { off }-\min }$ and $\mathrm{T}_{\mathrm{i}, \text { on-min }}$ indicates the minimum downtime and minimum runtime of the $\mathrm{i}^{\text {th }}$ unit respectively.

\subsection{Combined Weighted Dispatching Optimization Technique}

For the $i^{\text {th }}$ Objective Function $f_{i}(H)$, let $f_{i, \min }$ be the best solution of the $i^{\text {th }}$ object, and $f_{i, \min }>0$; Consider $\beta_{\mathrm{i}}$ indicates the elasticity degree of the $\mathrm{i}^{\text {th }}$ object, using an elasticity range of $\left(-\infty, \mathrm{f}_{\mathrm{i}, \min }+\beta_{\mathrm{i}} \mathrm{f}_{\mathrm{i}, \min }\right)$. Hence, the transfer function $\mu\left(\mathrm{f}_{\mathrm{i}}(\mathrm{H})\right)$ of the objective function $\mathrm{f}_{\mathrm{i}}(\mathrm{H})$ is represented as (12).

$$
\mu\left(\mathrm{f}_{\mathrm{i}}(\mathrm{H})\right)=\left\{\begin{array}{l}
\frac{1}{\mathrm{f}_{\mathrm{i} \text {,min }}+\beta_{\mathrm{i}} \mathrm{f}_{\mathrm{i} \text {,min }}-\mathrm{f}_{\mathrm{i}}(\mathrm{H}),} \\
\beta_{\mathrm{i}} \mathrm{f}_{\mathrm{i}, \text { min }} \quad \mathrm{f}_{\mathrm{i}, \text { min }} \leq \mathrm{f}_{\mathrm{i}}(\mathrm{H}) \leq \mathrm{f}_{\mathrm{i}, \text { min }}+\beta_{\mathrm{i}} \mathrm{f}_{\mathrm{i}, \text { min }} \\
0 \quad \mathrm{f}_{\mathrm{i}}(\mathrm{H})>\mathrm{f}_{\mathrm{i}, \text { min }}+\beta_{\mathrm{i}} \mathrm{f}_{\mathrm{i}, \text { min }}
\end{array}\right.
$$

During this transfer function, a combined weighted dispatching optimization method of the power system is represented as eq. (13).

$$
\begin{aligned}
& \text { s.t }\left\{\begin{array}{l}
\sum_{\mathrm{i}=1}^{\mathrm{N}_{\mathrm{G}}}\left(\mathrm{P}_{\mathrm{Hi}}(\mathrm{t}) \mathrm{S}_{\mathrm{i}, \mathrm{t}}\right)-\mathrm{P}_{\mathrm{d}}(\mathrm{t})-\mathrm{P}_{\mathrm{rc}}(\mathrm{t})=0 \\
\mathrm{~N}_{\mathrm{i}=1}\left(\mathrm{P}_{\mathrm{Hi}, \max } \mathrm{S}_{\mathrm{i}, \mathrm{t}}\right) \geq \mathrm{P}_{\mathrm{d}}(\mathrm{t})\left(1+\mathrm{R}_{\mathrm{t}+} \%\right) \\
\sum_{\mathrm{i}=1}^{\mathrm{N}_{\mathrm{G}}}\left(\mathrm{P}_{\mathrm{Hi}, \min } \mathrm{S}_{\mathrm{i}, \mathrm{t}}\right) \leq \mathrm{P}_{\mathrm{d}}(\mathrm{t})\left(1+\mathrm{R}_{\mathrm{t}-\mathrm{min}} \% \mathrm{P}_{\mathrm{Hi}}(\mathrm{t}) \leq \mathrm{P}_{\mathrm{Hi}, \max }\right.
\end{array}\right. \\
& \mathrm{P}_{\mathrm{Hi}}(\mathrm{t}-1)-\mathrm{D}_{\mathrm{i}} \leq \mathrm{P}_{\mathrm{Hi}}(\mathrm{t}) \leq \mathrm{P}_{\mathrm{Hi}}(\mathrm{t}-1)+\mathrm{D}_{\mathrm{i}} \\
& 0 \leq \mathrm{t} \leq \mathrm{T} ; \mathrm{S}_{\mathrm{i}, \mathrm{t}} \in\{0,1\} ; \mathrm{i}=1,2, \ldots . ., \mathrm{N}_{\mathrm{G}}
\end{aligned}
$$




\section{Proposed Hybrid PSO and GSA Algorithm}

The most important aim of the proposed method is to merge the immense capability of social thinking (gbest) in the PSO approach using the local search ability of the GSA. Eq. (15) is exploited to integrate these two approaches:

$$
u_{i}(t+1)=r_{1} u_{i}^{t}(t)+c_{1} r_{2} a_{i}^{t}(t)+c_{2} r_{3}\left(g_{b \text { best }}(t)-y_{i}^{t}(t)\right) i=1,2, \ldots, N, k=1,2, \ldots . . n
$$

In eq. (14) $c_{1}$ and $c_{2}$ indicates positive constants; $u_{i}^{t}(t)$ indicates the velocity module of $i^{\text {th }}$ agent relating to $\mathrm{k}^{\text {th }}$ dimension at iteration $\mathrm{t} ; \mathrm{r}_{1}, \mathrm{r}_{2}$, and $\mathrm{r}_{3}$ indicates uniformly distributed arbitrary numbers in $[0,1] ; \mathrm{g}_{\text {best }} \mathrm{k}(\mathrm{t})$ indicates $\mathrm{k}^{\text {th }}$ the dimension of the optimal solution until now at iteration $\mathrm{t} . \mathrm{a}_{\mathrm{i}}^{\mathrm{t}}(\mathrm{t})$ indicates the acceleration module of $i^{\text {th }}$ agent concerning $k^{\text {th }}$ dimension at iteration $t ; N$ indicates the number of agents, a well as $\mathrm{n}$ indicates the search space dimension of the issue. In each iteration, the locations of agents are updated as below:

$$
y_{i}(t+1)=y_{i}^{k}(t)+u_{i}(t+1), i=1,2, \ldots, N, k=1,2, \ldots . . n
$$

In the proposed method, all agents are at first pointlessly initialized. Subsequently, the gravitational constant and ensuing forces between agents are computed exploiting Eq. (17) and (18), respectively. G represents the gravitational constant, $y_{j}^{d}(t)$ and $y_{i}^{d}(t)$ defines the locations of particle $j$ andiat time $t$. The interaction forces $\mathrm{F}_{\mathrm{ij}}^{\mathrm{d}}(\mathrm{t})$ at a time $\mathrm{t}$ are subsequently calculated for all masses, $\varepsilon$ indicates a small constant, $y_{i}^{d}(t)$ denotes the location of $i^{\text {th }}$ agent $d^{\text {th }}$ dimension.

$$
\begin{aligned}
& G(t+1)=G(t) \exp \left(\frac{-a t}{T_{\text {max }}}\right) \\
& F_{i j}^{d}(t)=G(t)\left(\frac{M_{p t}(t) * M_{p t}(t)}{R_{i j}(t) * \varepsilon}\right)\left(y_{j}^{d}(t)-y_{i}^{d}(t)\right) \\
& a_{i}^{d}(t)=\left(\frac{F_{i}^{d}(t)}{M_{i j}(t)}\right)
\end{aligned}
$$

Subsequent to that, the accelerations of agents are decided based on the Eq. (19). After computing the accelerations and updating the optimal solution in each iteration, all agent's velocities are attained by exploiting the Eq. (14). Consequently, the locations of agents are updated by Eq. (15) and continue to reach $\mathrm{T}_{\max }$ or there is no enhancement for twenty sequence iteration.

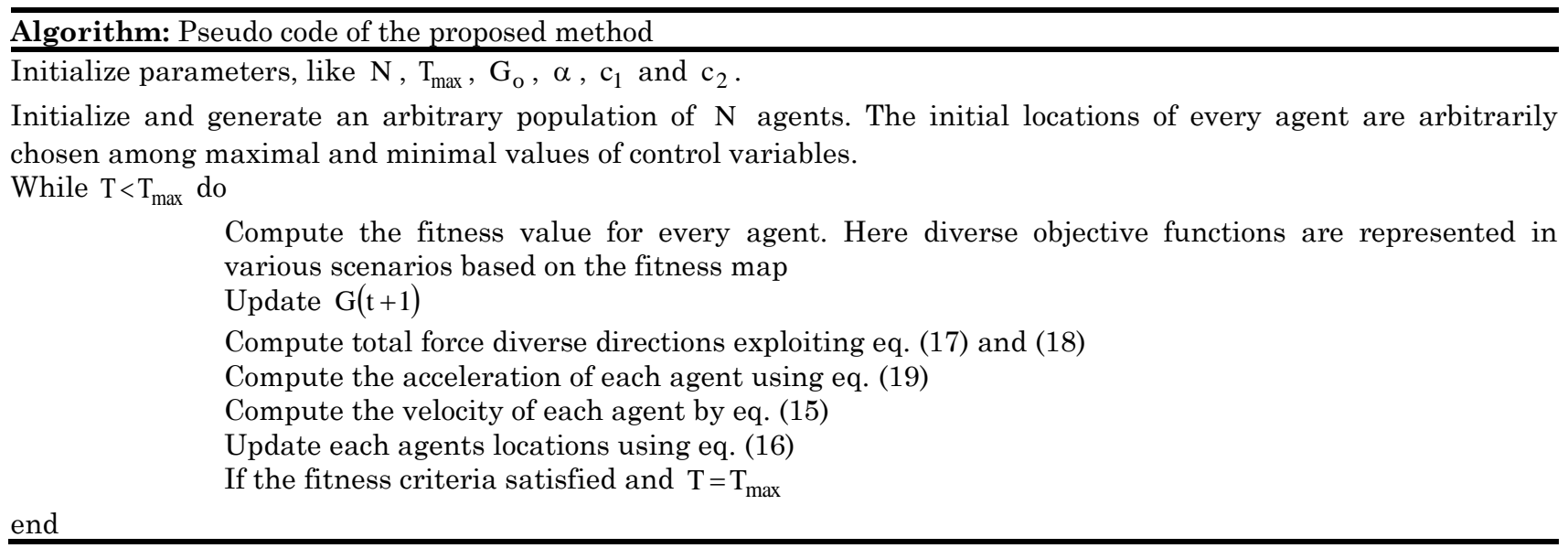

\section{Results and Discussions}

\subsection{Experimental Procedure}

In this paper, outcomes for 5-unit dispatching issues were calculated to examine outcomes of the proposed method also; it verifies the possibility of the method. Moreover, to test the calculation power of the Hybrid approach for high-dimensional complex data, and further this work has computed dispatching outcomes of 10 units. 


\subsection{Performance Analysis}

Table 1 summarizes the system parameters for the case study for 10 unit numbers. Table 2 summarizes the comparison of the proposed method with the conventional methods, and finally obtained the minimum cost of electricity purchase about minimum computation time for both the population sizes of 30 and 200 .

Table 1: System parameters for a case study of 10 units

\begin{tabular}{cllllllll}
$\begin{array}{c}\text { Unit } \\
\text { number }\end{array}$ & \multicolumn{3}{c}{$\begin{array}{c}\text { Coal consumption coefficient } \\
\text { (ton/hour) }\end{array}$} & \multicolumn{2}{c}{ Coefficient of Nox $\left(\mathbf{1 0}^{-\mathbf{7}} \mathbf{t o n} / \mathbf{h o u r}\right)$} & Output limit(MW) \\
\cline { 2 - 9 } & $\mathrm{l}_{\mathrm{i}}$ & $\mathrm{m}_{\mathrm{i}}$ & $\mathrm{n}_{\mathrm{i}}$ & $\mathrm{q}_{\mathrm{i}}$ & $\mathrm{w}_{\mathrm{i}}$ & $\mathrm{e}_{\mathrm{i}}$ & $\mathrm{P}_{\mathrm{Hi}, \min }$ & $\mathrm{P}_{\mathrm{Hi}, \mathrm{max}}$ \\
\cline { 2 - 9 } $\mathbf{1}$ & 0.116 & 2 & 6.49 & -5.554 & 4.091 & 150 & 470 & 0.00042 \\
$\mathbf{1}$ & 0.1105 & 5 & 5.629 & -6.047 & 1.542 & 125 & 460 & 0.00062 \\
$\mathbf{2}$ & 0.1091 & 7 & 4.596 & -5.094 & 4.157 & 72 & 240 & 0.00029 \\
$\mathbf{4}$ & 0.129 & 2 & 2.29 & -2.550 & 5.216 & 60 & 200 & 0.0007 \\
$\mathbf{5}$ & 0.1161 & 5 & 4.596 & -5.094 & 4.159 & 72 & 600 & 0.00079 \\
$\mathbf{6}$ & 0.1791 & 4 & 6.49 & -5.554 & 4.091 & 57 & 570 & 0.00056 \\
$\mathbf{7}$ & 0.1651 & 6 & 5.629 & -6.047 & 1.542 & 10 & 700 & 0.00111 \\
$\mathbf{9}$ & 0.1212 & 5 & 4.596 & -5.094 & 4.157 & 47 & 415 & 0.0049 \\
$\mathbf{9}$ & 0.1959 & 2 & 2.29 & -2.550 & 5.216 & 10 & 660 & $0.10,909$ \\
$\mathbf{1 0}$ & 0.1154 & 4 & 4.596 & -5.094 & 4.159 & 55 & 610 & 0.00951 \\
\hline
\end{tabular}

Table 2: Comparison analysis of the proposed and conventional methods

\begin{tabular}{|c|c|c|c|c|c|}
\hline Population size & Methods & Coal consumption & $\begin{array}{c}\text { Electric } \\
\text { power cost }\end{array}$ & $\begin{array}{l}\text { Carbon } \\
\text { emission }\end{array}$ & Computing time \\
\hline \multirow[t]{3}{*}{30} & PSO & $41,014.17$ & $16,814.18$ & 16 & $11,019.15$ \\
\hline & AFSA & $19,557.40$ & $16,765.19$ & 18 & $10,994.11$ \\
\hline & proposed method & $19,111.16$ & $16,511.56$ & 8 & $10,911.11$ \\
\hline \multirow[t]{3}{*}{200} & PSO & $41,158.61$ & $17,011.18$ & 84 & $11,719.15$ \\
\hline & AFSA & $40,181.16$ & $16,951.54$ & 69 & $11,088.45$ \\
\hline & proposed method & $41,405.45$ & $16,754.79$ & 45 & $14,981.06$ \\
\hline
\end{tabular}

\section{Conclusion}

In this work, the load distribution problem in diverse periods presented multiple objectives in present research fields of power market was focused. To give diverse weights to diverse objectives to convert multi-objective optimization issues into fuzzy single-objective optimization issues, and to attain the solution by exploiting the idea of utmost fulfillment was developed. In a real application, the weight coefficient of every objective might be dynamically attuned consistent with circumstances there and subsequently, and dynamically assign different output units to attain optimal amalgamation of resources and equipment, thus producing utmost profit for power enterprises.

In the field of power system dispatching, a Hybrid Algorithm was developed for challenging problems. This technique could resolve large-scale computation issues in a rapid and precise way. After the evaluation of the computation time, the proposed method was exhibited excellent benefits in saving computation time. Further, this work recommended an appropriate population size to use this method. At present, few frequently met issues in a solution of OPF issues such as huge computation quantities, least computation speed, and incapability to whole optimization computation in minimum time. Moreover, it hopes that power enterprises may enhance computation effectiveness by the aid of this method, and to attain optimized power system dispatching.

\section{References}

[1] L. Bai, M. Ye, C. Sun and G. Hu, "Distributed Economic Dispatch Control via Saddle Point Dynamics and Consensus Algorithms," in IEEE Transactions on Control Systems Technology, volume. 27, number. 2, page no. 898-905, March 2019.

[2] Z. Tang, D. J. Hill and T. Liu, "A Novel Consensus-Based Economic Dispatch for Microgrids," in IEEE Transactions on Smart Grid, volume. 9, number. 4, page no. 3920-3922, July 2018.

[3] Y. Zhang, M. H. Hajiesmaili, S. Cai, M. Chen and Q. Zhu, "Peak-Aware Online Economic Dispatching for Microgrids," in IEEE Transactions on Smart Grid, 8. volume. 9, number. 1, page no. 323-335, Jan. 2018. 
[4] M. Khalid, "Wind Power Economic Dispatch - Impact of Radial Basis Functional Networks and Battery Energy Storage," in IEEE Access, volume. 7, page no. 36819-36832, 2019.

[5] M. Garcia and R. Baldick, "Approximating Economic Dispatch by Linearizing Transmission Losses," in IEEE Transactions on Power Systems, volume. 35, number. 2, page no. 1009-1022, March 2020.

[6] G. Chen and Z. Zhao, "Delay Effects on Consensus-Based Distributed Economic Dispatch Algorithm in Microgrid," in IEEE Transactions on Power Systems, volume. 33, number. 1, page no. 602-612, January. 2018.

[7] H. Xue, Y. Bai, H. Hu, T. Xu and H. Liang, "A Novel Hybrid Model Based on TVIW-PSO-GSA Algorithm and Support Vector Machine for Classification Problems," in IEEE Access, volume. 7, page no. 27789-27801, 2019.

[8] Chithra.S and R.Madahana Kumari,"Economic Emission Dispatch in Renewable Energy Systems using FireFly Algorithm",Journal of Computational Mechanics, Power System and Control (JCMPS), Volume 1, Issue 1, October 2018.

[9] SK.Mahammad Shareef and Dr.R.Srinivasa Rao,"A Hybrid Learning Algorithm for Optimal Reactive Power Dispatch under Unbalanced Conditions", Journal of Computational Mechanics, Power System and Control (JCMPS), Volume 1, Issue 1, October 2018.

[10] Rekha .P. Nair,Kanakasabapathy P,"Hybrid PSO-BF Algorithm for Economic Dispatch of a Power System",Journal of Computational Mechanics, Power System and Control (JCMPS), Volume 2, Issue 2, April 2019.

[11] Raj Kumar,"Hybrid Cat Swarm and Crow Search Algorithm to Solve the Combined Economic Emission Dispatch Model for Smart Grid",Journal of Computational Mechanics, Power System and Control (JCMPS),Volume 2, Issue 3, July 2019.

[12] Sadashiv Halbhavi B,Kodad S F,Ambekar S K,Manjunath D,"Enhanced Invasive Weed Optimization Algorithm with Chaos Theory for Weightage based Combined Economic Emission Dispatch",Journal of Computational Mechanics, Power System and Control (JCMPS), Volume 2, Issue 3, July 2019. 